transmitted to monkeys. The virus, unlike that which has been raised from epidemics in America and on the continent, has not yet produced a fatal disease in the monkeys.

Cases 3 and 4, therefore, occurred in a mild epidemic, whilst Case 1 was sporadic. This may be the explanation of the variation in the pathogenicity of the virus. The work of other investigators has shown that it is extremely difficult to transmit the virus from sporadic cases, whilst in epidemics transmission is successful in the great majority of instances.

We suggest, therefore, that in sporadic cases the virus is feeble, and the occurrence of the disease is due to a hypersusceptibility of the individual attacked, whilst an epidemic only results when the virus has become exalted either by a series of passages through susceptible individuals or from some other cause unknown. It seems probable that the virus has been gradually exalted during the last three years in the neighbourhood of the London Hospital, until a mild epidemic occurred in 1912. It will, therefore, be of great interest to note whether the pathogenicity increases in 1913.

We are greatly indebted to Dr. Henry Head for allowing us to publish his case, to the members of the medical staff of the London Hospital for permission to make use of the clinical notes on the patients under their care, to Dr. E. G. Fearnsides, medical registrar, for valuable assistance, and to the administrators of the London Hospital Medical College Research Fund for a grant towards the expenses.

Bibliography.-1. S. Flexner and P. A. Lewis: Journal of American Medical Association, 1910, vol. liii., p. 1913. 2. S. Flexner: THE LANCET, Nov. 9th, 1912, p. 1271. 3. W. Knoepfelmacher: Medizinische Klinik, 1909, Band i., p. 1671. 4. K. Landsteiner and E. Popper: Zeitschrift für Immunitätsforschung, Orig., 1909, Band ii., p. 377. 5. C. Levaditi and K. Landsteiner: Comptes Rendus de la Société de Biologie, 1910, vol. Ixviii., p. 264. 6. C. Levaditi, Gordon, and Danulesco : Ibid., 1911, vol. Ixxi., 651. 7. C. Leiner and R. Wiesner: Wiener klinische Wochenschrift, 1909, Band xxii., p. 1698. 8. A. Maximow: Experimentelle Untersuchungen iiber die entzündliche Neubildung von Bindegewebe, Ziegler's Beiträge, Finftes Supplement Heft, 1902. 9. A. Maximow Ziegler's Beiträge, 1903, Band xxxiv., p. 153, and 1904, Band xxxv., p. 93. 10. P. H. Römer: Münchener Medizinische Wochenschrift, 1909, Band Ivi.. p. 2505. 11. P. H. Römer : Die Epidemische Kinderlahmung, Berlin, 1911, Springer. 12. I. Strauss and F. M. Huntoon : New York klinische Wochenschrift, 1912, Band xlix., p. 63 . 14. J. Wickman : Die Akute Poliomyelitis, Berlin, 1911, Springer.

December, 1912.

\section{TWO CASES OF PANCREATIC CYST.}

\section{BY W. F. CHOLMELEY, F.R.C.S. ENG.}

HONORARY SURGEON TO THE GENERAI HOSPITAY, WOLVERHAYPTON.

CASE 1.-The patient, a male, aged 19, came under my care with symptoms of intestinal obstruction. He had absolute constipation and had vomited. The abdomen was not much distended, there was no vomiting or marked tenderness, nor could a "lump" be felt. The attack had come on quite suddenly with acute pain in the epigastrium, and had been followed by vomiting. Enemata and purgatives were tried, but without effect. After four days, during which time every endeavour was made to get an action of the bowels, I decided to explore the abdomen, even though the patient did not look as ill as cases of intestinal obstruction usually do. I looked upon the case of one of enterospasm.

The abdomen was opened in the middle line below the umbilicus, and there appeared to be nothing wrong. There was no excess of fluid, no injection of the peritoneum, nor were the intestines much distended. The wound was closed and the patient taken back to bed. The next day the bowels opened quite naturally. The urine was tested twice before the operation, and no sugar was found. A day or two after the operation the patient began to complain of attacks of colic in the epigastric region. At first nothing abnormal could be felt, but the epigastrium began to swell quickly, and became tender. By the end of 10 days a definite tumour made its appearance in the epigastrium, and caused a good deal of pressure on the transverse colon. During the attacks of colic the bowel could be seen moving over the lower part of the tumour, and the colic disappeared as soon as the contents of the bowel had passed along with a gurgling sound. The urine was again tested and found to contain sugar. then diagnosed a pancreatic cyst, and decided to open the abdomen and drain.

Sixteen days after the first operation I opened the abdomen in the middle line above the umbilicus, and over the most prominent part of the tumour. The cyst was found to be pushing its way between the stomach and the transverse colon. The general peritoneal cavity was packed of by gauze swabs, and the cyst tapped with a full-sized trocar and cannula. A large amount of thin, yellowish-coloured fluid was drawn off, full of what looked like cholesterin crystals. There did not seem to be any definite cyst wall beyond the thickened peritoneum of the lesser sac. This was sutured to the parietal peritoneum and a large bore rubber tube fixed in the cyst. The wound was sewn up to the tube.

Little need be said about the further progress of the case. Within 24 hours the fluid draining away from the cyst caused intense irritation of the skin, which was with difficulty kept within bounds. The patient made an uninterrupted recovery, the sinus taking three months to heal. The glycosuria disappeared in a fortnight. About the fourth day after the operation there was a sudden rush of bilestained fluid from the cyst, which flooded the dressings and soaked the bed. For some time after this the discharge contained a good deal of bile. Unfortunately the full notes of this case have been lost, so that the gaps have to be filled in from memory.

CASE 2.-The patient, a lady aged 75, came under my care in December, 1911. The history obtained is as follows. The patient had an attack of acute abdominal pain about the second week in September. This lasted about four hours, There was no vomiting, and the pain was chiefly in the left hypochondrium and right iliac fossa. Shortly after this attack she began to notice that her clothes were feeling tighter round the abdomen, and she suffered from thirst A second attack of pain occurred at the end of November, lasted much longer, and was accompanied by vomiting, and more or less intestinal obstruction for five days. 'I'his was relieved by repeated doses of calomel, and oil enemata given through a long tube. She had had some diarrhoa and what was thought to be indigestion for a few weeks before. Th pain was situated in the same place as in the former attack. After this second attack there was increased thirst.

I first saw the patient on Dec. 22nd. She then looked extremely ill, the abdomen was so swollen that she was unable to fasten her clothes properly, the tongue was very dry and coated, and she complained very much of thirst. The patient found it impossible to sit in one position for a long time, and could not sit upright at all on account of the pain it caused, no doubt due to the pressure on the cyst. On the evening of the same day she had an attack of very acute pain in the abdomen, chiefly in the epigastrium. On examination, a swelling was felt occupying the whole of the epigastrium and about the size of a full-term child's head. The tumour was smooth, tense, and elastic, not very tender, and was dull over the upper part, and faintly resonant over the lower. Though the pain was evidently very acute, there was no collapse, and the pulse remained good. The acute pain lasted about three hours, but she was not quite free from all pain until the next morning. 'The urine was tested and found to contain sugar, $10 \mathrm{gr}$. to the ounce. There was no polyuria. I looked upon the case as one of pancreatic cyst, but on account of the patient's extreme weakness did not feel justified in advising operation. On Dec. 25th Mr. E. Deanesly very kindly saw her with me, confirmed my diagnosis, and advised no operation. He suggested a slightly restricted diet and codeia $\frac{1}{2}$ gr. twice a day.

The patient gradually improved under this treatment, and though there were at times some colicky pains, she had no acute attack. The amount of sugar slowly decreased, and at the beginning of the third week in January had disappeared. The cyst gradually grew larger, and began to give trouble by pressing on the stomach or colon, I could not be certain which. During the third week in January the restricted diet began to pall and irritate the patient, who became anxious for something to be done to relieve her. As her general condition had greatly improved, and there was no longer any glycosuria, I decided to operate.

On Jan. 21st the patient was anæsthetised by Dr. E. W. Strange, a mixture of chloroform and ether being used, and assisted by Mr. A. H. W. Hunt I opened the abdomen in the middle line above the umbilicus and over the most prominent part of the tumour. Tha cyst was seen to be pushing 
its way above the stomach. As the slightest attempt to get below the stomach to drain the cyst brought on the most alarming collapse, it was thought best to drain above the stomach, and finish the operation as quickly as possible. After carefully tearing through the gastro-hepatic omentum, I tapped the cyst with a large-sized aspirating needle, and drew off 3 pints of chocolate-coloured fluid. When no more fluid would come away, the opening in the cyst was carefully enlarged, until I could introduce my finger. A good deal of débris could be felt in the cyst, a large quantity of it being fairly firmly adherent to the lower part of the cyst wall. Some of it was removed for examination, and looked like a mixture of sloughs and old blood clot. The wall of the cyst was $\frac{1}{8}$ in. thick, and seemed as if it would peel out with ease. I did not try to peel it out, as the patient's condition would not allow of a long operation, and $I$ was well aware of the pitfalls awaiting me should I attempt it. The cyst wall was sutured to the abdominal wall, a large rubber tube fixed in, and the wound sewn up.

The patient stood the operation very well and had very little pain after. The discharge very quickly caused intense irritation of the surrounding skin. As was expected, sugar appeared in the urine immediately after the operation and remained until Feb. 1st. On Jan. 29th there was a sudden rush of a large amount of bile-stained fluid mixed with mucus. This was repeated about a week later, and each time soaked through the dressings and flooded the bed. For some time small sloughs and other débris came away when dressing the patient, being brought up by syringing with hydrogen peroxide. On Feb. 19th a large slough, 3 inches long and 1 inch broad, came away. The patient was allowed up in a fortnight. No diabetic diet was given after the operation, and the codeia was stopped when the sugar disappeared. The further progress of the case was excellent until March 8th, when she was seized with an attack of acnte bronchitis which nearly proved fatal. Glycosuria appeared again when the bronchitis started and did not again disappear. The patient was allowed out of bed on May 2nd and went away on July 11th. It was unfortunate that in this case the cyst could not be drained below the stomach, at its most most dependent part, as it was bound to take very much longer to fill up. When the patient left there was still a long sinus present.

The fluid in the first case was proved to contain pancreatic secretion, but I have not the report by me. The reports on the second case I append, and were made by the Clinical Research Assaciation :- " The fluid is of a dark colour, it is faintly alkaline, has a specific gravity of 1010, and an albumin content of 0.7 per cent. There is no evidence of proteid digestion or fat splitting, but there is conversion of starch. The centrifugalised deposit is considerable in amount, and consists of many blood discs, a small number of leucocytes, an occasional epithelial cell, and much fat débris, part of which occurs as neutral fat, and in fatty acid crystals. The specimen is non-purulent in character, but a fair number of Gram-negative bacilli are seen to be present. On culture these are coliform in type."

The report on the piece of débris is:-"This material is far too necrosed for a definite opinion to be given. We feel morally certain, however, that it is pancreatic tissue. There are many areas which suggest fat necrosis, and some parts suggest outlines like those of pancreatic acini. There are many masses of cells filled with blood pigment, and in the centre there is a fibrous nodule containing a duct. It is difficult to see why so large a fibrous mass should form round a pancreatic duct, but that is clearly the suggestion. There is no evidence of malignant growth."

The first case was undoubtedly a pseudo-cyst, the attack simulating intestinal obstruction being caused by the rupture of an old cyst into the closed lesser peritoneal sac. I did not drain directly the cyst, but the lesser sac. The second case I look upon as a true pancreatic cyst. There seemed to be a definite cyst wall $\frac{1}{s}$ in. thick, which would have peeled out, to some extent at least, with great ease-not what would be expected of the peritoneum of the lesser sac.

The etiology of the second case I take to be as follows A large retention cyst had formed as the result of chronic pancreatitis. The fibrous nodule round a duct seen under the microscope suggests the chronic pancreatitis. The attacks of acute pain were caused by hæmorrhages into this cyst, while the attack at the end of November was one of acute pancreatitis, most probably hæmorrhagic, involving that part of the pancreas to which the cyst was more directly connected. There had no doubt been some very acute pancreatic mischief, or how are the sloughs to be explained? I do not think that the acute pain on the evening of Dec. 21st was caused by another hæmorrhage, as the cyst was not more tender than it had been, and the pulse never failed in the least. There was, however, every reason for a hæmorrhage at that time, as the patient had been a railway journey of 70 miles that day.

Both patients at the present time are doing very well, though the second case still has a sinus and a slight amount of glycosuria.

Wolverhampton.

\section{TWO CASES OF PANCREATIC CYST WITH ACUTE SYMPTOMS.}

\section{BY CLAUDE FRANKAU, M.B. LoND., F.R.C.S. ENG.,} ASSISTANT SURGEON TO ST. GEORGE'S HOSPITAL.

CYsTS in connexion with the pancreas are not in them. selves very uncommon; the onset of acute and urgent symptoms as the first indication of the presence of such cysts is, however, of sufficient rarity to warrant a note on two such cases which have recently been under my care at St. George's Hospital.

CASE 1. - The patient, a female, aged 46, was admitted into St. George's Hospital on Sept. 24th, 1911, and gave the following history. For three weeks she had had abdominal pain of a spasmodic character ; this at first was not severe, and was mainly referred to the navel; later it became more marked, and for the four days prior to admission had been almost continuous, and had shifted to the right hypochondriac region. In addition to the increased severity of the pain there had been also almost incessant vomiting of bile-stained fluid in small quantities and absolute constipation for five days. Her health had previously been excellent there had been no jaundice. The only previous medical history of any importance was that of a somewhat doubtful abdominal injury some 20 years previously.

On examination the patient was an extremely wellnourished woman. The expression was anxious and she was clearly in pain; at frequent intervals small quantities of bile were vomited. The tongue was furred; temperature $100^{\circ} \mathrm{F}$. and pulse 104. The abdomen showed considerable general distension, but moved well; on palpation an extremely tender, rounded swelling could be felt somewhat below and immediately to the right of the navel. This was quite localised and fixed; it was dull to percussion, with an area of resonance above and below it. The size of the swelling was roughly that of a man's fist. The remainder of the abdomen showed no abnormality apart from some general tenderness. As enemata produced no result and the symptoms persisted operation was decided upon four hours after admission.

Operation.-A three-inch incision was made over the centre of the swelling through the outer border of the right rectus; on opening the peritoneum a small amount of free fluid escaped; there was no peritonitis. The swelling was found to be a tense retroperitoneal cyst presenting below the transverse mesocolon, and apparently of pancreatio origin. After packing off the intestines with gauze the cyst was incised, and $45 \mathrm{cz}$. of dark-brown fluid were evacuated. At the bottom of the cyst a hard, rounded body of the size of a walnut was found and removed; this proved to be composed of layers of dried blood clot. A large drainage tube was then sewn into the cyst and the abdominal wall partly closed; a gauze plug was also left in belcw the tube. The fluid from the cyst was deeply blood-stained and contained a large amount of albumin; the reaction was alkaline. Trypsin was present in considerable quantity, as well as a diastatic ferment.

The urine passed before the operation contained a trace of albumin, and also gave a faint reduction with Fehling's solution; this reduction persisted for about four weeks and then disappeared; the urine at the present time is quite normal.

The patient made a good recovery from the operation, and 